\title{
Mulheres e telenovela: a recepção pela perspectiva das relações de gênero
}

\section{Veneza Mayora Ronsini e Renata Córdova da Silva}

\section{Resumo}

0 objetivo deste texto é apresentar reflexões sobre a

recepção da telenovela, problematizando questões

de gênero. Para ilustrar os apontamentos teóricos

utilizamos dados de uma etnografia crítica da recepção

realizada com seis mulheres das classes populares, três

mães e suas respectivas filhas, residentes na cidade de

Santa Maria/RS. Os resultados demonstram que apesar das telenovelas apresentarem diversas possibilidades para 0 feminino, o espaço doméstico ainda é retratado como essencialmente ligado às mulheres. Esse discurso é assimilado totalmente pelas mães entrevistadas e parcialmente pelas filhas. Estas, talvez pelo maior nível de escolaridade em relação às mães, não aceitam tão facilmente a separação entre esfera pública para os homens e esfera privada para as mulheres, buscando a conciliação da maternidade com a atividade profissional, já que a autonomia financeira é um ideal para elas.

\section{Palavras-chave:}

Recepção. Telenovela. Gênero. Identidade feminina.

\section{Introdução}

A vertente britânica dos estudos culturais, constituída no final dos anos de 1950 a partir do pensamento de Richard Hoggart, Raymond Williams e Edward Palmer Thompson, passou a incorporar uma preocupação com temáticas feministas e com os meios de comunicação de massa a partir da década de 1970. É também nessa década, que os estudos feministas começam a utilizar de forma mais incisiva a categoria gender (gênero), reivindicando que houvesse uma distinção entre 0 sexo como marca biológica e 0 gênero como resultado de construções sociais e culturais. Essa distinção entre sexo e gênero era uma forma de enfrentar o determinismo biológico, segundo o qual as características humanas consideradas femininas eram derivadas naturalmente do seu sexo.

0 feminismo trouxe para os estudos culturais o debate acerca das questões de gênero como fator relevante ao lado da classe no processo de construção das identidades. Além disso, os textos midiáticos e seus receptores passaram a
Doutora em Sociologia pela Universidade de São Paulo - USP. Professora do Programa de Pós-Graduação em Comunicação da Universidade Federal de Santa Maria - UFSM. Pesquisadora do CNPq.

Renata Córdova da Silva I rr_cordova@yahoo.com.br Mestre em Comunicação pela Universidade Federal de Santa Maria UFSM. Bolsista da Coordenação de Aperfeiçoamento de Pessoal de Nível Superior - CAPES (agosto 2009/março 2011). 
ser valorizados, sendo a influência do feminismo importante, entre outros aspectos, "[...] para 0 entendimento do âmbito pessoal como político [...]", para "[...] a expansão da noção de poder, que, embora bastante desenvolvida, tinha sido apenas trabalhada no espaço da esfera pública [...]" e para "[...] a inclusão de questões em torno do subjetivo e do sujeito [...]" (ESCOSTEGUY, 2001, p. 31).

Na América Latina, pesquisas sobre mulheres e mídia começaram a ser realizadas no final da década de 1960 vinculadas à teoria crítica da comunicação. Essas investigações buscaram compreender o papel dos meios na consolidação de um modelo feminino hegemônico e ainda como essa forma dominante de representar a mulher serve de guia para a constituição das identidades de gênero (CHARLES, 1996, p. 39). Primeiramente, os trabalhos enfocavam as mensagens dos meios de comunicação. É só a partir dos anos 1980 que as investigações centram-se nos receptores.

No âmbito dos estudos culturais latinoamericanos, as primeiras pesquisas de recepção de produtos midiáticos por mulheres, apesar de terem forte influência dos estudos culturais britânicos, não problematizavam o universo feminino e utilizavam a categoria gênero somente para indicar a distinção entre os sexos feminino e masculino ${ }^{1}$ (ESCOSTEGUY, 2001). No entanto, aprofundar a análise nas questões de gênero traz um novo olhar sobre as receptoras, já que permite novas formas de interpretar 0 universo das entrevistadas, negando a existência de uma essência feminina e entendendo como as relações sociais são organizadas a partir de diferenças sexuais de forma que a dominação de gênero seja vista como natural, ao passo que é algo construído culturalmente e sujeito a mudanças (BOURDIEU, 2007).

Quanto à recepção, nós a percebemos como parte do processo de comunicação, seguindo 0 pensamento de Martín-Barbero (1987) no que se refere ao estudo das relações entre receptores e mídia. 0 autor considera que a recepção não é apenas um momento, mas sim um processo que antecede e prossegue a ação de ver televisão e deve ser visto dentro de um espaço mediado. Lopes, Borelli e Resende (2002, p. 32) explicam que para essa tradição teórica, a recepção é "[...] um contexto complexo multidimensional, em que as pessoas vivem o seu cotidiano. Ao mesmo tempo, ao viverem este cotidiano inscrevem-se em relações de poder estruturais e históricas, as quais extrapolam suas práticas cotidianas".

Entender a recepção sob a ótica do gênero pode nos ajudar a desvendar as conexões entre 0 consumo de bens midiáticos pelas mulheres e as constantes negociações de poder no interior das famílias. Além disso, pode ser a chave para compreendermos de que forma a mídia atua na reprodução da desigualdade de gênero ao mesmo 
tempo em que pode contribuir para a contestação dessa desigualdade. Radway (1984) conseguiu, por exemplo, relacionar o consumo de romances de série à resistência a valores patriarcais ${ }^{2}$ enraizados em nossa sociedade, na medida em que suas entrevistadas encontravam espaço em meio à rotina dos afazeres domésticos para ler, ou seja, interrompiam as tarefas para se dedicarem a elas mesmas.

Charles (1996, p. 43) acredita que problematizar as questões de gênero no estudo da recepção nos ajuda a perceber "[...] como e por que a mulher se aproxima de diferentes meios de comunicação, em que contexto recebe suas mensagens e que uso faz delas em sua vida”. Assim, é possível relacionar a mídia ao universo cultural e social das entrevistadas para descobrirmos os sentidos da apropriação dos meios.

Tendo esses apontamentos em vista, a proposta deste artigo é refletir sobre o imaginário teleficcional e suas conexões com o cotidiano das receptoras a partir do aporte das relações de gênero. Ilustramos as teorias aqui expostas com dados obtidos em uma etnografia crítica da recepção (RONSINI, 2010) realizada com seis mulheres das classes populares - três mães e suas respectivas filhas - residentes na cidade de Santa Maria, no Rio Grande do $\mathrm{Sul}^{3}$.

\section{Mídia e identidade feminina}

Ao tomarmos a identidade como o produto das relações que cada pessoa estabelece com os outros (com outras pessoas, instituições, situações sociais etc.), notamos que ela está relacionada às atividades sociais em que os indivíduos estão envolvidos. Casseti e Di Chio (1999, p. 319) assinalam que "[...] a intervenção dos meios eletrônicos desarticula os processos tradicionais de construção de identidade, através de novas experiências e de novas formas de socialização". A televisão, especialmente a ficção televisiva, apresenta uma gama de personagens que possibilitam processos de identificaçã $0^{4}$. A mídia é, assim, parte importante na construção da identidade dos sujeitos sociais, pois fornece

"0 patriarcado pode ser considerado um relacionamento social em que os homens dominam, exploram e oprimem as mulheres. Como conceito, define as relações desiguais entre os gêneros, embora nem todos os homens, ou todas as mulheres, sejam igualmente favorecidos ou desfavorecidos. Outras estruturas de desigualdade, como classe e raça, precisam também ser consideradas" (STRINATI, 1999, p. 193-194).

A classificação social das entrevistadas (classes populares: média baixa e baixa) foi definida mediante a metodologia da estratificação sócio-ocupacional, na qual a família é classificada a partir do membro melhor situado economicamente (QUADROS; ANTUNES, 2001). Neste estudo, considera-se a classe social não só como um fator socioeconômico evidenciado por indicativos como renda e escolaridade, mas também como um aspecto sociocultural. Seguindo Mattos (2006, p. 162), compreende-se que "[...] o conceito de classe não está ligado tão-somente ao lugar que o indivíduo ocupa na produção, ou seja, a uma dimensão econômica, mas também a uma dimensão sociocultural que está relacionada a determinadas percepções de mundo".

Processo pelo qual o sujeito se constitui e se transforma (ROUDINESCO; PLON, 1998, p. 363). Frequentemente diz-se que as pessoas se projetam em determinado personagem de romances ou telenovelas. Para LAPLANCHE e PONTALIS (1992), esse processo deveria antes ser classificado no campo daquilo que os psicanalistas chamam de identificação, já que a projeção para a psicanálise tem um sentido restrito: modo de defesa em que o sujeito rejeita ou desconhece em si qualidades, sentimentos e desejos, atribuindo-os a uma alteridade que the é externa. 
"[...] o material com que as pessoas forjam sua identidade" (KELLNER, 2001, p. 9).

$\mathrm{Na}$ atualidade, entre outros processos, as instituições que eram a base de pertencimento dos sujeitos sociais, como a família, a escola e a Igreja, passam por uma constante desestabilização.

Isso incide no processo de constituição das identidades que se transformam conforme as experiências a que somos submetidos. Hall (2007, p. 108) considera que as identidades são "[...] multiplamente construídas ao longo de discursos, práticas e posições que podem se cruzar ou ser antagônicas. As identidades estão sujeitas a uma historicização radical, estando constantemente em processo de mudança e transformação".

Para Hall (1997b), os sujeitos formam a sua identidade culturalmente. É a forma como negociamos com nossas vivências, ou seja, com a cultura que vai estabelecer o que somos, ou melhor, o que estamos constantemente nos tornando. Se aceitarmos que a identidade está em permanente processo de construção, não podemos concordar com uma essência feminina, que nasce com as mulheres e as predispõe a determinados comportamentos. A identidade de gênero, assim como a identidade social, é produto da sociedade e da cultura em que estamos inseridos, não é nunca algo acabado.

Simone de Beauvoir (2009, p. 928) foi pioneira em contestar a ideia de "natureza feminina". Para a autora, "nada é natural na coletividade humana", com isso "[...] a mulher é um produto elaborado pela civilização". No mesmo ano em que Beauvoir lançou O segundo sexo, 1949, Margareth Mead inaugurou o uso do termo gênero. Ficavam assim diferenciados o sexo (marca biológica) e o gênero (construção social).

Com o desenvolvimento das lutas feministas e dos estudos sobre a mulher ficou cada vez mais claro que a desigualdade entre homens e mulheres não é natural, mas própria da vida em sociedade. Para Haraway (2004, p. 211), o conceito de gênero contesta a naturalização da diferença sexual. "A teoria e a prática feminista em torno de gênero buscam explicar e transformar sistemas históricos de diferença sexual nos quais homens e mulheres são socialmente constituídos e posicionados em relações de hierarquia e antagonismo".

Ao serem socializados, os sujeitos aprendem a ser, a se comportarem como mulheres e homens em um processo de negociação de sentidos, que envolve 0 ambiente doméstico, escolar, do trabalho, enfim, a vida social como um todo. Bourdieu (2007, p. 82) acredita que desde a infância uma série de rupturas faz com que os homens adotem uma postura viril, enquanto as meninas continuam a conviver com a postura "feminilizante" da mãe. Para 0 autor, as mulheres são ensinadas a pensar e a agir de determinada maneira, não expondo partes do corpo, sendo delicadas, servindo aos outros. Isso evidencia uma socialização sexista, que incentiva desde uma forma de vestir mais confortável para os meninos até a maior liberdade de ação, enquanto tudo isso é reprimido nas meninas. 
Uma pesquisa realizada pela Fundação Perseu Abramo em 2001 aponta que $96 \%$ das mulheres entrevistadas são responsáveis pelo trabalho doméstico em suas casas e apenas 10\% recebem ajuda de seus maridos. Nos lares em que residem filhos menores de idade, $29 \%$ das filhas ajudam no trabalho doméstico, contra $9 \%$ dos filhos (VENTURI; RECEMÁN; OLIVEIRA, 2004). Apesar das diversas conquistas do movimento feminista, ainda é comum que o processo de socialização dos jovens seja conduzido por uma educação sexista.

Em relação às mães e às filhas que fazem parte desta pesquisa, nota-se que a educação sexista recebida pelas mães em suas famílias de origem, com uma autoridade paterna muito forte dividindo claramente os papéis do homem e da mulher, foi fundamental para assimilarem a ideologia dominante com relação à submissão feminina. Entre as filhas, isso é visto em menor grau. 0 acesso à escola, a falta da figura paterna e a desestabilização da família talvez tenham contribuído para o maior questionamento da autoridade masculina e a introjeção de valores referentes à importância do trabalho e de certa autonomia na vida da mulher. No entanto, isso não é fundamental para todas. Muitas vezes, 0 trabalho e a autonomia vêm em segundo plano, pois o primordial é o casamento e a maternidade, apesar das entrevistadas enfatizarem 0 discurso da mulher batalhadora que se afirma pela sua profissão. Acreditamos, como Mattos (2006, p. 158), que esse ideal da mulher que conseguiu sair da esfera doméstica, luta por igualdade de salários e de relações com seus parceiros sejam "[...] vivenciados apenas pelas mulheres de classe média atingindo as classes populares de forma residual [...]", isto é, torna-se apenas um discurso, uma vontade, mas ainda é uma realidade muito distante do cotidiano das entrevistadas.

Essa dualidade que acompanha as mulheres na contemporaneidade entre a vida privada (e os papéis de mãe, esposa e dona-de-casa) e a vida pública (a construção de uma carreira profissional bem sucedida, autonomia financeira) está presente também nas telenovelas. A ficção televisiva fornece um arsenal de personagens que não são uma imagem única do feminino. Há diversas (e contraditórias) maneiras de se retratar a mulher, contudo algumas formas são culturalmente mais legítimas do que outras. Junqueira (2009) assinala que desde a década de 1980 há um aumento dos tipos femininos nas telenovelas, gerando mais possibilidades de identificação entre as telespectadoras. No entanto, esta abertura para novas possibilidades do feminino não veio acompanhada de uma discussão sobre os reais problemas enfrentados pelas mulheres em seu cotidiano. As telenovelas não abordam a razão nem os mecanismos que legitimam a dominação masculina na sociedade. Hamburger (2007) também enfatiza essa posição, afirmando que enquanto a saída da mulher da esfera privada e sua entrada no mercado de trabalho é legitimada nas telenovelas, questões referentes à divisão das tarefas domésticas e dos 
cuidados com os filhos não são abordadas nas tramas 0 que acaba colaborando com um ideal de supermulher, que acumula uma jornada dupla de trabalho e tem que desempenhar bem as funções de mãe, esposa e profissional.

Além disso, a telenovela, devido a sua matriz melodramática, possui uma narrativa centrada na história de pares românticos, estando fortemente ligada a ideais do amor romântico (MEIRELLES, 2009). Os obstáculos impostos ao amor, retardando a reunião do casal; 0 triângulo amoroso e a ascensão social pelo casamento estão presentes nas telenovelas (COSTA, 2000). Três outros aspectos podem ser ressaltados: a relação das mulheres com a maternidade, a crença das heroínas no amor romântico e a sua passividade erótica. Esses aspectos são naturalizados como próprios da essência feminina (COSTA, 2000, p. 94).

Essas concepções ligadas aos valores do amor romântico contribuíram durante muitos anos para manter as mulheres no espaço privado, pois refletiam valores patriarcais presentes na sociedade ao idealizar o ser amado e a ideia da maternidade, ser incompatível com a sensualidade e incentivar a passividade sexual feminina e disseminar a busca de alguém que nos completará, crença que por vezes fez do casamento o objetivo primário das mulheres. Por outro lado, estamos vivendo um período de grandes transformações, em que a mulher cada vez mais busca 0 seu espaço no ambiente público e tem maior autonomia sexual na medida em que a sexualidade é desvinculada da sua função reprodutiva (GIDDENS, 1993).

Há, então, uma tensão entre os valores conservadores a respeito da maternidade, do amor e da sexualidade e os valores desta sociedade em transformação. A partir disso, tanto a mídia quanto as receptoras negociam sentidos na construção do que é o feminino.

\section{Mulher, telenovela e representação}

Para Hall (1997a), representar é realizar um trabalho contínuo de atribuir sentido ao mundo que nos cerca. Na mídia, muitas vezes esse processo se naturaliza, fazendo as representações aparentemente perderem o seu caráter de permanente construção e serem apreendidas como a forma correta de mostrar a sociedade. As representações que circulam na mídia são construídas a partir de um processo dinâmico em que a mídia influencia e é influenciada pela sociedade. Esse processo instaura modelos de como ser mulher no mundo contemporâneo que podem ou não ser assimilados pelas receptoras de acordo com as vivências das mesmas.

Contudo, ao atentarmos nossa análise à perspectiva do gênero, nos damos conta de que a vivência das entrevistadas está atrelada à cultura em que estamos inseridos que por sua vez atribui às mulheres um status desigual em relação aos homens. Para Bourdieu (2007), a dominação de gênero está historicamente apoiada 
em instituições, como a Família, a Igreja, a Escola e 0 Estado que reproduzem através dos séculos mecanismos reforçadores de uma sociedade desigual. Na visão do autor, há uma naturalização dessa estrutura de dominação, sendo esquecidos os processos históricos que a propiciaram. Isso nos faz pensar que as divisões sexuais estabelecidas são amparadas em fundamentos biológicos e, portanto, imutáveis, quando na verdade são fruto de uma construção cultural sujeita a mudanças.

A força da dominação exercida pelos homens em nossa sociedade se evidencia na medida em que ela não precisa ser justificada, "[...] a visão androcêntrica impõe-se como neutra e não tem necessidade de se enunciar em discursos que visem a legitimá-la" (BOURDIEU, 2007, p. 18). 0 autor acredita que somente a tomada de consciência - de que muitas vezes as próprias mulheres reproduzem dentro de seus lares as estruturas de dominação e que os homens encontram-se igualmente presos em um processo sufocante que dita regras de comportamento tanto para dominados quanto para dominantes - fará com que esse processo histórico e cultural comece a se modificar.

Devemos lembrar também que nenhuma situação de dominação é levada por tanto tempo sem 0 consentimento do dominado. Para Colling (2004), sem a noção de consentimento não é possível falar em gênero, pois ele está tão entranhado na vida de homens e mulheres, que é assumido pelas pessoas sem elas darem-se conta de que ele existe. As mulheres acabam por assumir o discurso dominante que atribui maior poder aos homens na esfera política. 0 consentimento é fundamental "[...] no funcionamento de um sistema de poder [...], devendo ser objeto de estudo a dominação masculina também como dominação simbólica, que supõe a adesão das próprias dominadas a categorias e sistemas que estabelecem a sujeição" (COLLING, 2004, p. 18).

Saffioti (1992, p. 184) nos alerta que a relação entre homens e mulheres, entre outras relações de exploração ou dominação, não pressupõe "[...] 0 total esmagamento da personagem que figura no pólo de dominada-explorada". Devemos entender que é justamente o contrário, a relação se sustenta com "a preservação da figura subalterna". № entanto, a subalternidade da mulher "[...] não significa ausência absoluta de poder. Com efeito, nos dois pólos da relação existe poder, ainda que em doses tremendamente desiguais".

Observando as entrevistadas desta pesquisa, notamos que elas têm dificuldades em abrir mão do papel de "rainhas do lar". 0 poder que a idealização da maternidade possibilitou ao feminino dentro das famílias é considerável e, muitas vezes, as mulheres não estão dispostas a abrir mão desse poder, cobrando de seus companheiros uma divisão igualitária das tarefas domésticas e do cuidado com os filhos. $0 \mathrm{~s}$ principais argumentos são que "os homens não sabem limpar como as mulheres", que "eles não 
são organizados para manter a casa em ordem sozinhos" e que "eles não têm jeito para cuidar das crianças pequenas". Com isso, elas também são responsáveis por esse ideal da mulher que "dá conta de tudo" e enfrenta uma dupla jornada de trabalho para ser boa mãe, esposa e profissional.

Um dos pontos mais polêmicos em relação à natureza feminina é a maternidade. Badinter (1985) realizou uma extensa pesquisa histórica e concluiu que 0 amor materno é uma construção do nosso tempo, não existindo em todas as épocas com a força que existe hoje. A autora considera que 0 instinto materno é um mito, ele não é determinado biologicamente e que a mãe e o pai podem desenvolver o mesmo tipo de amor pelos filhos. 0 amor materno é um comportamento social que varia conforme a época, não há uma conduta materna universal, mas uma diversidade de formas desse sentimento, que não faz parte da natureza feminina, mas é adquirido.

No entanto, a maternidade segue sendo bastante idealizada. Isso se reflete inclusive no número restrito de pais que conseguem a guarda de seus filhos em casos de divórcio. Para quatro das entrevistadas, a maternidade é algo fundamental para defini-las como mulher. Elas afirmam que a maternidade é a "coisa mais importante na vida de uma mulher" e que "as mulheres foram feitas para dar a luz". As entrevistadas também consideram que as mães têm um laço de amor e entrega em relação aos filhos maior do que o dos pais. Esse discurso pode ser fruto da falta de estabilidade da figura masculina nas famílias observadas. Em duas delas os pais abandonaram as filhas e em uma delas a divisão entre o pai provedor e a mãe dona-de-casa é muito clara, já que o homem não permite que a mulher trabalhe fora de casa, sendo esta responsável pela organização do lar. Apenas em uma das famílias, a mãe confessou ter refletido sobre a possibilidade de não engravidar, mas acabou cedendo ao desejo de seus companheiros que sempre quiseram ter filhos. Para a filha desta entrevistada, a maternidade não faz parte dos planos para o futuro e sim a continuidade dos estudos e a construção de uma carreira profissional. A renda das três famílias é equivalente, com isso, neste caso, o que parece fazer com que uma delas tenha foco na profissão enquanto as outras sonham com o casamento e a maternidade é a relação familiar. A primeira faz parte de um lar caótico em que predomina a violência física e simbólica, as segundas têm admiração pela figura materna, sendo esta sinônimo de "carinho" e "força".

A idealização da maternidade e da figura feminina como eixo do lar também está presente nas telenovelas. Em Passione ${ }^{5}$, transmitida pela Rede Globo no horário das 21 horas, Jéssica (Gabriela Duarte) é um personagem, que com seu tom cômico, poderia questionar um pouco o papel da maternidade na vida da mulher. Jéssica não 
gosta de ficar o dia todo tomando conta do filho, inclusive pediu para que seu pai arrumasse uma babá para que ela pudesse acompanhar o marido em seu trabalho. 0 argumento utilizado pela moça para convencer o pai a fazer a sua vontade foi que ela havia estudado e precisava acompanhar de perto como o pai e o marido estavam gerenciando o patrimônio que um dia seria dela e de seu filho. No entanto, a verdadeira intenção de Jéssica era vigiar o marido, ficando perto dele o máximo de tempo possível. Suas atitudes fúteis passam a ideia de uma mãe displicente e desinteressada. Entre as outras mães da telenovela, Bete (Fernanda Montenegro) e Candê (Vera Holtz) trabalham, e apesar de serem bastante dedicadas aos filhos e à família, não ficam restritas ao espaço doméstico. Bete tem grande poder de decisão na família e em sua empresa. Candê é chefe de família. Agostina (Leandra Leal) também trabalha, mas não possui a autonomia de Bete e Candê. Já Felícia (Larissa Maciel) e Stela (Maitê Proença) não trabalham. 0 fato de não trabalhar restringe a vida social de Felícia e a aprisiona em um cotidiano de afazeres domésticos e cuidados com a família que não a realiza totalmente. 0 caso de Stela é diferente. Ela nasceu em uma família rica e aguentou a estupidez do marido, até 0 momento da morte dele, por querer manter a família unida.

Outro aspecto interessante nas telenovelas é a relação entre mulheres e trabalho. Comparando as profissões de homens e mulheres em Passione, observamos que os homens possuem mais cargos de chefia, enquanto há o predomínio de mulheres como secretárias e empregadas domésticas. Entre as mulheres, as profissões de maior destaque são as de Bete, que dirigiu por um tempo a Metalúrgica Gouveia, e Melina (Mayana Moura), que é estilista. Na classe popular, destacam-se a inescrupulosa Valentina (Daisy Lucidi), dona de uma pensão, e Candê, que possui uma banca na CEAGESP (Companhia de Entrepostos e Armazéns Gerais de São Paulo) onde vende verduras. Para Agostina, que é restauradora, a profissão não parece importante, pois ela a largou para ir atrás do marido no Brasil. Três personagens são secretárias (Jaqueline - Alexandra Richter, Myrna - Kate Lyra, e Lurdinha - Simone Gutierrez), duas são empregadas domésticas (Olga - Débora Duboc e Guida - Andrea Bassit), quatro são donas-de-casa (Stela, Felícia, Clô - Irene Ravache e Gemma - Aracy Balabanian), Diana (Carolina Dieckmann) e Laura (Adriana Prado) são jornalistas e Lorena (Tammy Di Califiori) é estudante. Já entre os homens, com exceção de Agnello (Daniel de Oliveira), que não quer trabalhar e sim ser sustentado pelo pai, eles são definidos pela profissão. Totó (Tony Ramos) é lavrador de terras e é ajudado pelos filhos Adamo (Germano Pereira) e Alfredo (Miguel Roncato). Olavo (Francisco Cuoco) é empresário e Berilo (Bruno Gagliasso) tem um cargo na empresa do sogro. Mauro (Rodrigo Lombardi) e Saulo (Werner Schünemann) são executivos da Metalúrgica Gouveia. Noronha (Rodrigo 
dos Santos) e Dr. Cavarzere (Giulio Lopes) são advogados. Sinval (Kayky Brito) e Danilo (Cauã Reymond) são ciclistas, Chulepa (Gabriel Wainer) é treinador dos atletas e Gerson (Marcello Antony) é corredor de Stock Car. Na classe popular temos o chofer Diógenes (Elias Gleiser), o sapateiro Nonno (Emiliano Queiroz), o carteiro Mimi (Marcelo Médici) e o mordomo Arthurzinho (Julio Andrade). Com este último personagem, se reforça a ideia de que o espaço doméstico é uma atribuição feminina, pois Arthurzinho é o único personagem homossexual da novela.

A telenovela retrata a divisão sexual do trabalho presente em nossa sociedade que, entre outros elementos, foi fundamental para que os cuidados com as crianças fossem exercidos pelas mulheres. Essa divisão do papel de cada gênero é tão arraigada em nossa sociedade que é tida como "natural". Para rompermos com essa ideia é preciso entender que "[...] a mulher, como sujeito social que se afirma, não é uma realidade homogênea e monolítica, mas vive, existe na concretude das diferenças sociais e culturais que a constituem" (FRANCHETTO; CAVALCANTI; HEILBORN, 1981, p. 43).

Ao compreendermos que não há uma essência feminina que dite comportamentos para as mulheres, percebemos a infinidade de diferenças que marcam o "tornar-se mulher". Nesse processo, a etnia/raça, a faixa etária, a classe social, a escolaridade, entre outros fatores vão fazer com que cada mulher viva uma trajetória distinta.
No entanto, Venturi, Recamán e Oliveira (2004) acreditam que os constrangimentos a que as mulheres brasileiras são submetidas tanto na esfera pública quanto na privada podem lhes conferir uma identidade de gênero marcada pela opressão.

Entre as entrevistadas desta pesquisa essa opressão é bastante evidente. 0 acesso precário ao mercado de trabalho, a falta de escolaridade e de acesso a bens culturais, aliados a uma educação sexista e conservadora colaboram para que essas mulheres tenham uma vivência marcada pela violência física e simbólica. Somente uma das entrevistadas relatou nunca ter sofrido nenhum tipo de violência. Na maioria das vezes, a violência é praticada pelos parceiros por meio de "tapas" e ofensas verbais. Contudo, nenhuma disse sentir-se discriminada por ser mulher. Para elas, as ofensas não são uma forma de discriminação. Uma das entrevistadas chegou a definir a violência como própria da vida a dois.

Os homens das famílias das entrevistadas costumam impor a sua vontade de duas formas: pelo respeito que as mulheres invariavelmente têm por eles e por meio da força física. Nas famílias de origem das mães, os homens eram respeitados como a autoridade máxima da casa e sua vontade nunca era questionada. Na casa de uma delas, 0 pai era violento e ela acabou se envolvendo com homens violentos no decorrer de sua vida. Entre as filhas a tolerância à violência parece ser menor. 0 nível de escolaridade (ainda que precário e com diversas interrupções) parece ser a maior ruptura 
da geração das filhas com relação à das mães e pode ser uma explicação para a não aceitação da violência e a maior procura por autonomia financeira.

Hall (2003) considera que ao estudarmos a cultura popular devemos ter em mente 0 caráter de transformação que é intrínseco a ela, pois é nela que se travam as lutas do consentimento e da resistência. As entrevistadas deste estudo estão sempre tendo que negociar com um ideal de mulher moderna, que é próprio da contemporaneidade e por isso mesmo está presente nas telenovelas, e 0 seu cotidiano marcado pela opressão e pela carência de recursos materiais e simbólicos.

\section{Considerações finais}

A relação entre meios e receptores é bastante complexa, ainda mais quando buscamos desvendar de que modo a mídia contribui para a constituição das identidades dos sujeitos. Algumas vezes, as receptoras ao consumir a telenovela concordam, aderem, realizam uma leitura preferencial da representação da mulher nas telenovelas. Em Passione, Jéssica, a personagem que poderia contrapor um valor patriarcal (segundo o qual a existência feminina está ligada à possibilidade da mulher ser mãe, e assim, cuidar e educar os filhos, a mulher só fica completa e se realiza quando se torna mãe, portanto essa ideologia não deixa margem para que a mulher possa não ter vocação para a maternidade e escolher não ter filhos), com a ideia de que a maternidade não precisa impedir que a mulher retorne ao mercado de trabalho e tenha outros interesses além do cuidado com a casa, o marido e os filhos, na verdade o reforça. Ao apresentar Jéssica como uma patricinha fútil cuja única preocupação é saber o paradeiro do marido, a telenovela endossa 0 valor da maternidade, pois a moça passa a ser apontada como negligente em relação ao filho.

Nenhuma das entrevistadas quer ser como Jéssica. Para elas, a personagem é "desnaturada com o filho", "metidinha", "péssima mãe", "desocupada", "chata" e "nojentinha". No caso estudado a adesão ao discurso dominante em relação à maternidade ocorre porque as mães tiveram uma educação sexista, em que os homens deveriam ser os provedores da família e as mulheres donas-de-casa e mães de família. Mesmo as que possuíam famílias de origem muito pobres e começaram a trabalhar bastante jovens apresentam esse pensamento como sendo o mais "correto". Como elas não tiveram acesso a uma boa educação formal, não tem hábito de leitura e nem uma vida social ativa, elas concordam que a maternidade é parte essencial do ser mulher. As entrevistadas foram educadas para pensar assim e transmitem isso para suas filhas, reproduzindo a educação sexista que receberam. No entanto, como as filhas têm um contexto de vida diferente do que as mães tiveram, o discurso dominante a respeito da maternidade é assimilado, mas com ressalvas, já que a divisão sexual do trabalho não é tão aceita. Nenhuma das filhas quer ser exclusivamente dona-de-casa e todas pensam em conciliar a maternidade com 0 trabalho. 
As receptoras aderem ou se opõem à

representação da mulher de acordo com suas vivências. A mídia pode reforçar pensamentos que já são das receptoras, mas também pode apresentar algo novo, que não faz parte visão de mundo e da experiência das entrevistadas. Como a liberada Stela, que mantinha casos extraconjugais com rapazes mais jovens como válvula de escape para a vida infeliz que levava junto ao marido. As telenovelas, ao longo do tempo vêm quebrando tabus e veiculando diversas possibilidades para o feminino. Há personagens que são mulheres fortes, que possuem autonomia financeira e grande poder de decisão no ambiente profissional e doméstico, como Bete Gouveia. No entanto, a desigualdade entre os gêneros não é questionada nas telenovelas. 0 ambiente doméstico, por exemplo, é reforçado como essencialmente feminino, o que parece legitimar que a subordinação das mulheres é tratada nas tramas a partir da "natureza" feminina e não como uma questão social.

\section{Referências}

ALMEIDA, Heloisa Buarque de. Telenovela, consumo e gênero: "muitas mais coisas". Bauru, SP: EDUSC, 2003.

BADINTER, Elisabeth. Um amor conquistado: o mito do amor materno. Rio de Janeiro: Nova Fronteira, 1985.

BEAUVOIR, Simone de. 0 segundo sexo. Rio de Janeiro: Nova Fronteira, 2009.
BOURDIEU, Pierre. A dominação masculina. Rio de Janeiro: Bertrand Brasil, 2007.

CASETTI, Francesco; DI CHIO, Federico. Analisis de la Television. Buenos Ayres, Ediciones Paidós Ibérica, 1999.

CHARLES, Mercedes. Espejo de Venus: una mirada a la investigación sobre mujeres y medios de comunicación. Signo y Pensamiento, n. 28, p. $37-50,1996$.

COLLING, Ana. A construção histórica do feminino e do masculino. In: STREY, Marelene Neves; Cabeda, Sonia T. Lisboa; Prehn, Denise Rodrigues. Gênero e cultura: questões contemporâneas. Porto Alegre: EDIPUC, 2004.

COSTA, Cristiane. Eu compro essa mulher: romance e consumo nas telenovelas brasileiras e mexicanas. Rio de Janeiro: Jorge Zahar, 2000.

ESCOSTEGUY, Ana Carolina. Cartografias dos estudos culturais: uma versão latino-americana. Belo Horizonte: Autêntica, 2001.

FRANCHETTO, Bruna; CAVALCANTI, Maria Laura; HEILBORN, Maria Luiza. Antropologia e feminismo. In: FRANCHETTO, Bruna et al. (Org.). Perspectivas antropológicas da mulher. Rio de Janeiro: Zahar Editores, 1981.

GIDDENS, Anthony. As transformações da intimidade: sexualidade, amor e erotismo nas sociedades modernas. São Paulo: Unesp, 1993.

HALL, Stuart. The work of representation. In: 
HALL, Stuart (Org.). Representation: cultural representation and cultural signifying practices. London/Thousand 0aks/New Delhi: Sage/Open University, 1997a.

. A centralidade da cultura: notas sobre as revoluções culturais de nosso tempo. Educação \& Realidade, Porto Alegre, v. 22, n. 2, p. 15-46, 1997 b.

. Notas sobre a

desconstrução do "popular". In: SOVIK, Liv. Da diáspora: identidades e mediações culturais. Belo Horizonte: Editora UFMG, 2003.

Quem precisa de

identidade? In: SILVA, Tomaz Tadeu da. (Org.).

Identidade e diferença. A perspectiva dos

Estudos Culturais. Petrópolis: Vozes, p. 103-133, 2007.

HAMBURGER, Esther. A expansão do "feminino" no espaço público brasileiro: novelas de televisão nas décadas de 1970 e 80. Revista Estudos Feministas, v. 15, n. 1, p. 153-175, 2007.

HARAWAY, Donna. "Gênero" para um dicionário marxista: a política sexual de uma palavra. Cadernos Pagu, Campinas, n. 22, p. 201-246, 2004.

JUNQUEIRA, Lília. Desigualdades sociais e telenovelas: relações ocultas entre ficção e reconhecimento. São Paulo: Annablume, 2009.

KELLNER, Douglas. A cultura da mídia: estudos culturais: identidade e política entre o moderno e o pós-moderno. Bauru, SP: EDUSC, 2001.

LAPLANCHE, Jean; PONTALIS, Jean-Bertrand. Vocabulário da psicanálise. São Paulo: Martins Fontes, 1992.

LOPES, Maria Immacolata Vassalo.; BORELLI, Silvia Helena Simões.; RESENDE, Vera da Rocha. Vivendo com a telenovela: mediações, recepção, teleficcionalidade. São Paulo: Summus, 2002.

MARTÍN-BARBERO, Jesús. De los medios a las mediaciones. Barcelona: Gustavo Gili, 1987.

MATTOS, Patrícia. A mulher moderna numa sociedade desigual. In: SOUZA, Jessé. A

invisibilidade da desigualdade brasileira. Belo Horizonte: Editora UFMG, 2006.

MEIRELLES, Clara Fernandes. Prazer e resistência: A legitimação do melodrama nos contextos acadêmicos. Dissertação (Mestrado em Comunicação e Cultura), 212 p. Universidade Federal do Rio de Janeiro, Rio de Janeiro, 2009.

MESSA, Márcia Rejane P. As mulheres só querem ser salvas: Sex and the City e o pós-feminismo. Dissertação (Mestrado em Comunicação), 139 p. Pontifícia Universidade Católica do Rio Grande do Sul, Porto Alegre, 2006.

QUADROS, Waldir J. de; ANTUNES, Davi J. N. Classes sociais e distribuição de renda no Brasil dos anos noventa. Cadernos do CESIT, n. 30, out. 2001. Disponível em < http://www.eco.unicamp. br.publicacoes.html>. Acesso em: 14 jul. 2004. 
RADWAY, J. Reading the romance: women, patriarchy and popular literature. Chappel Hill: University of North Carolina Press, 1984.

ROUDINESCO, Eisabeth; PLON, Michel.

Dicionário de psicanálise. Rio de Janeiro: Jorge Zahar, 1998.

RONSINI, Veneza Mayora. A perspectiva das mediações de Jesús Martín-Barbero (ou como sujar as mãos na cozinha da pesquisa empírica de recepção). In: XIX Encontro da Compós. Rio de Janeiro, 2010.

SAFFIOTI, Heleieth I. B. Rearticulando gênero e classe social. In: COSTA, Albertina de Oliveira; BRUSCHINI, Cristina. Uma questão de gênero. Rio de Janeiro: Rosa dos Tempos; São Paulo: Fundação Carlos Chagas, 1992.

SCOFIELD, Thereza Helena Prates.

Possibilidades do feminino: as telespectadoras de Ponta Porá e as mulheres do Mais Você.

Dissertação (Mestrado em Comunicação), 142

p. Universidade Federal de Minas Gerais, Belo

Horizonte, 2007.

SIFUENTES, Lírian. Telenovela e a identidade feminina de jovens de classe popular.

Dissertação (Mestrado em Comunicação), 239 p.

Universidade Federal de Santa Maria, Santa Maria, 2010.

STRINATI, Dominic. Cultura popular: uma introdução. São Paulo: Hedra, 1999.

VENTURI, Gustavo; RECAMÁN, Marisol;
OLIVEIRA, Suely de. A mulher brasileira nos espaços público e privado. São Paulo: Editora Fundação Perseu Abramo, 2004. 
Women and telenovela: the media reception from the perspective of gender

\section{Mujeres y telenovela: receptión desde la perspectiva de las relaciones de género}

\section{Abstract:}

The aim of this paper is to present reflections on the reception of telenovela, discussing gender issues. To illustrate the theoretical approaches we used data from a critical ethnography of reception held with six women working class, three mothers and their daughters, living in Santa Maria/RS. The results show that despite the telenovelas present several possibilities for feminine, domestic space is still portrayed as essentially linked to women. This discourse is fully assimilated by those mothers and partly by their daughters who not so easily accept the separation between the public sphere for men and women to the private sphere, seeking to reconcile motherhood with professional activity, as financial autonomy is an ideal for them. These findings probably are due to their higher level of education when compared with educational level of the mothers.

\section{Keywords:}

Reception. Telenovela. Gender. Feminine identify.

\section{Resumen:}

El objetivo de este trabajo es presentar reflexiones sobre la recepción de las telenovelas, discutiendo las cuestiones de género. Para ilustrar los enfoques teóricos, usamos los datos de una etnografía crítica de la recepción con seis mujeres de la clase obrera, tres madres y sus hijas, que viven en Santa María/ RS. Los resultados muestran que a pesar de las telenovelas presentes varias posibilidades para el femenino, lo espacio doméstico es tratado todavía como esencialmente vinculado con las mujeres. Este discurso está totalmente asimilado por las madres y en parte por sus hijas. Estas, tal vez por un mayor nivel de educación en comparación con las madres, no aceptan tan fácilmente la separación entre la esfera pública para los hombres y las mujeres a la esfera privada, tratando de conciliar la maternidad con la actividad profesional, como la autonomía financiera es un ideal para ellas.

\section{Palabras clave:}

Recepcíon. Telenovela. Género. Identidad femenina. 


\section{Expediente}

A revista E-Compós é a publicação científica em formato eletrônico da Associação Nacional dos Programas de Pós-Graduação em Comunicação (Compós). Lançada em 2004, tem como principal finalidade difundir a produção acadêmica de pesquisadores da área de Comunicação, inseridos em instituições do Brasil e do exterior.

\section{E-COMPÓS I www.e-compos.org.br I E-ISSN 1808-2599}

Revista da Associação Nacional dos Programas de Pós-Graduação em Comunicação.

Brasília, v.14, n.1, jan/abr. 2011

A identificação das edições, a partir de 2008

passa a ser volume anual com três números.

\section{CONSELHO EDITORIAL}

Afonso Albuquerque, Universidade Federal Fluminense, Brasil Alberto Carlos Augusto Klein, Universidade Estadual de Londrina, Brasil Alex Fernando Teixeira Primo, Universidade Federal do Rio Grande do Sul, Brasil Ana Carolina Damboriarena Escosteguy, Pontifícia Universidade Católica do Rio Grande do Sul, Brasil

Ana Gruszynski, Universidade Federal do Rio Grande do Sul, Brasil Ana Silvia Lopes Davi Médola, Universidade Estadual Paulista, Brasil André Luiz Martins Lemos, Universidade Federal da Bahia, Brasil Ângela Freire Prysthon, Universidade Federal de Pernambuco, Brasil Angela Cristina Salgueiro Marques, Faculdade Cásper Líbero (São Paulo), Brasil Antônio Fausto Neto, Universidade do Vale do Rio dos Sinos, Brasil Antonio Carlos Hohlfeldt, Pontifícia Universidade Católica do Rio Grande do Sul, Brasil Antonio Roberto Chiachiri Filho, Faculdade Cásper Líbero, Brasil Arlindo Ribeiro Machado, Universidade de São Paulo, Brasil Arthur Autran Franco de Sá Neto, Universidade Federal de São Carlos, Brasil Benjamim Picado, Universidade Federal Fluminense, Brasil César Geraldo Guimarães, Universidade Federal de Minas Gerais, Brasil Cristiane Freitas Gutfreind, Pontifícia Universidade Católica do Rio Grande do Sul, Brasil Denilson Lopes, Universidade Federal do Rio de Janeiro, Brasil Denize Correa Araujo, Universidade Tuiuti do Paraná, Brasil Edilson Cazeloto, Universidade Paulista, Brasil Eduardo Peñuela Cañizal, Universidade Paulista, Brasil Eduardo Vicente, Universidade de São Paulo, Brasil Eneus Trindade, Universidade de São Paulo, Brasil Erick Felinto de Oliveira, Universidade do Estado do Rio de Janeiro, Brasil Florence Dravet, Universidade Católica de Brasília, Brasil Francisco Eduardo Menezes Martins, Universidade Tuiuti do Paraná, Brasil Gelson Santana, Universidade Anhembi/Morumbi, Brasil Gilson Vieira Monteiro, Universidade Federal do Amazonas, Brasil Gislene da Silva, Universidade Federal de Santa Catarina, Brasil Guillermo Orozco Gómez, Universidad de Guadalajara Gustavo Daudt Fischer, Universidade do Vale do Rio dos Sinos, Brasil Hector Ospina, Universidad de Manizales, Colômbia Herom Vargas, Universidade Municipal de São Caetano do Sul, Brasil leda Tucherman, Universidade Federal do Rio de Janeiro, Brasil Inês Vitorino, Universidade Federal do Ceará, Brasil Janice Caiafa, Universidade Federal do Rio de Janeiro, Brasil Jay David Bolter, Georgia Institute of Technology Jeder Silveira Janotti Junior, Universidade Federal de Pernambuco, Brasil João Freire Filho, Universidade Federal do Rio de Janeiro, Brasil
John DH Downing, University of Texas at Austin, Estados Unidos José Afonso da Silva Junior, Universidade Federal de Pernambuco, Brasil José Carlos Rodrigues, Pontifícia Universidade Católica do Rio de Janeiro, Brasil José Luiz Aidar Prado, Pontifícia Universidade Católica de São Paulo, Brasil José Luiz Warren Jardim Gomes Braga, Universidade do Vale do Rio dos Sinos, Brasil Juremir Machado da Silva, Pontifícia Universidade Católica do Rio Grande do Sul, Brasil Laan Mendes Barros, Universidade Metodista de São Paulo, Brasil Lance Strate, Fordham University, USA, Estados Unidos Lorraine Leu, University of Bristol, Grã-Bretanha Lucia Leão, Pontifícia Universidade Católica de São Paulo, Brasil Luciana Panke, Universidade Federal do Paraná, Brasil Luiz Claudio Martino, Universidade de Brasília, Brasil Malena Segura Contrera, Universidade Paulista, Brasil Márcio de Vasconcellos Serelle, Pontifícia Universidade Católica de Minas Gerais, Brasi Maria Aparecida Baccega, Universidade de São Paulo e Escola Superior de Propaganda e Marketing, Brasil

Maria das Graças Pinto Coelho, Universidade Federal do Rio Grande do Norte, Brasil Maria Immacolata Vassallo de Lopes, Universidade de São Paulo, Brasil Maria Luiza Martins de Mendonça, Universidade Federal de Goiás, Brasil Mauro de Souza Ventura, Universidade Estadual Paulista, Brasil Mauro Pereira Porto, Tulane University, Estados Unidos Nilda Aparecida Jacks, Universidade Federal do Rio Grande do Sul, Brasil Paulo Roberto Gibaldi Vaz, Universidade Federal do Rio de Janeiro, Brasil Potiguara Mendes Silveira Jr, Universidade Federal de Juiz de Fora, Brasil Renato Cordeiro Gomes, Pontifícia Universidade Católica do Rio de Janeiro, Brasil Robert K Logan, University of Toronto, Canadá

Ronaldo George Helal, Universidade do Estado do Rio de Janeiro, Brasil Rosana de Lima Soares, Universidade de São Paulo, Brasil Rose Melo Rocha, Escola Superior de Propaganda e Marketing, Brasil Rossana Reguillo, Instituto de Estudos Superiores do Ocidente, Mexico Rousiley Celi Moreira Maia, Universidade Federal de Minas Gerais, Brasil Sebastião Carlos de Morais Squirra, Universidade Metodista de São Paulo, Brasil Sebastião Guilherme Albano da Costa, Universidade Federal do Rio Grande do Norte, Brasil

Simone Maria Andrade Pereira de Sá, Universidade Federal Fluminense, Brasil Tiago Quiroga Fausto Neto, Universidade de Brasília, Brasil Suzete Venturelli, Universidade de Brasilia, Brasil

Valério Cruz Brittos, Universidade do Vale do Rio dos Sinos, Brasil Valerio Fuenzalida Fernández, Puc-Chile, Chile Veneza Mayora Ronsini, Universidade Federal de Santa Maria, Brasil Vera Regina Veiga França, Universidade Federal de Minas Gerais, Brasil

\section{COMISSÃO EDITORIAL}

Adriana Braga I Pontifícia Universidade Católica do Rio de Janeiro, Brasil Felipe Costa Trotta I Universidade Federal de Pernambuco, Brasil CONSULTORES AD HOC

Édison Gastaldo I Universidade Federal Rural do Rio de Janeiro, Brasil Gisela Grangeiro da Silva Castro, Escola Superior de Propaganda e Marketing, Brasil Helio Kuramoto, Instituto Brasileiro de Informação em Ciência e Tecnologia, Brasil Juliano Maurício de Carvalho, Universidade Estadual Paulista, Brasil Maria Helena Weber, Universidade Federal do Rio Grande do Sul, Brasi Paulo Carneiro da Cunha Filho, Universidade Federal de Pernambuco, Brasil Vera Regina Veiga França, Universidade Federal de Minas Gerais, Brasil EDIÇÃO DE TEXTO E RESUMOS I Susane Barros SECRETÁRIA EXECUTIVA I Juliana Depiné EDITORAÇÃo ELETRÔNICA I Roka Estúdio
COMPóS I www.compos.org.br

Associação Nacional dos Programas de Pós-Graduação em Comunicação

Presidente

Itania Maria Mota Gomes

Universidade Federal da Bahia, Brasil

itania@ufba.br

Vice-presidente

Julio Pinto

Pontifícia Universidade Católica de Minas Gerais, Brasil juliopinto@pucminas.br

Secretária-Geral

Ana Carolina Escosteguy

Pontifícia Universidade Católica do Rio Grande do Sul, Brasil carolad@pucrs.br 